\title{
O problema do abandono de animais domésticos e a importância da educação cidadã em uma escola de Educação Básica de Timbó Grande, Santa Catarina
}

\author{
The problem of abandonment of domestic animals and the importance of citizen \\ education in a Basic Education School in Timbó Grande, Santa Catarina
}

\author{
Joel Cezar Bonin ${ }^{1}$ \\ Sunah Jessie Makiolki ${ }^{2}$ \\ Levi Hülse ${ }^{3}$
}

\begin{abstract}
Resumo
O estudo demonstra que os animais domésticos são parte legítima da sociedade brasileira, pois quando se possui um animal doméstico, são assumidas certas responsabilidades como: alimentação adequada e cuidados médicos veterinários, o que, por vezes, é negligenciado pelos seus donos. Abandonar animais é caracterizado como uma forma de maus-tratos. $\mathrm{O}$ caminho percorrido neste trabalho foi o de apresentar por meio da Educação Ambiental, atividades na busca da promoção em uma escola de Educação Fundamental, de questões educacionais e ambientais correlatas ao abandono de animais por meio de oficinas temáticas, demonstrando, por exemplo, que esse abandono é muito amplo e com muitas consequências, tais como: superpopulação nas ruas, ataques de animais raivosos aos pedestres, ameaças à saúde pública, etc. Os estudantes envolvidos no estudo pertencem a uma escola de Educação Básica Estadual do município de Timbó Grande, Santa Catarina, sendo que participaram da pesquisa 20 alunos de uma turma de $6^{\circ}$ ano da escola, com idades aproximadas de 11 e 12 anos. Os dados foram coletados por meio de um questionário. Os resultados buscaram desenvolver nos alunos da escola, um senso mais humanizado no que se refere à compreensão do trato e dos cuidados com os animais. Infelizmente, vê-se um grande desprezo e abandono dos animais domésticos na cidade estudada. Dessa maneira, criar uma forma diferenciada de compreensão da importância da vida desses animais, a fim de conscientizar os alunos de que todo ser vivo tem direito à vida e aos cuidados necessários.
\end{abstract}

Palavras-chave: Abandono de Animais; Educação Ambiental; Proteção Animal.

\footnotetext{
${ }^{1}$ Doutor em Filosofia. Universidade Alto Vale do Rio do Peixe-UNIARP. Caçador, Santa Catarina, Brasil. Email: boninj7@gmail.com

${ }^{2}$ Mestre em Educação Básica, Universidade Alto Vale do Rio do Peixe-UNIARP, Timbó Grande, Santa Catarina, Brasil. E-mail: sunah_makiolki@hotmail.com

${ }^{3}$ Doutor e Mestre em Ciência Jurídica pela Universidade do Vale do Itajaí- UNIVALI - SC, na área de concentração em Constitucionalismo, Transnacionalidade e Produção do Direito. Bacharel em Direito pela Fundação Universidade Regional de Blumenau - FURB (2010) e graduado em História pela Fundação Universidade Regional de Blumenau FURB (2006). Advogado com a OAB/SC 31.986. Docente e pesquisador dos Programas de Pós-Graduação em Desenvolvimento e Sociedade e Profissional em Educação da Universidade Alto Vale do Rio do Peixe-UNIARP. E-mail: levi@uniarp.edu.br. cv lattes: http://lattes.cnpq.br/1833130032474610
}

Revista Devir Educação, Lavras, vol.2, n.4, p.251-271 jul./dez., 2020. 


\begin{abstract}
The study shows that domestic animals are a legitimate part of Brazilian society, because when you have a domestic animal (for example), certain responsibilities are assumed, such as adequate food and veterinary medical care, the which is sometimes overlooked by its owners. Abandoning animals is characterized as a form of ill-treatment, becoming a typified crime. In this sense, the path taken in this work was to present, through Environmental Education, activities in the search for promotion in an elementary school, of educational and environmental issues related to the abandonment of animals through thematic workshops, demonstrating, for example, that this abandonment is very wide and with many consequences, such as overpopulation on the streets, attacks of angry animals on pedestrians, threats to public health, etc. The students involved in the study belong to a State Basic Education school in the municipality of Timbó Grande, Santa Catarina, and 20 students from a 6th grade class of the school, aged between 11 and 12 years, participated in the research. The data were collected through a questionnaire. The results sought to develop in the school students, a more humanized sense with regard to understanding the treatment and care of animals. Unfortunately, one sees a great contempt and abandonment of domestic animals in the studied city. It was necessary to create a different way of understanding the importance of the life of these animals in order to make students aware that every living being has the right to life and the necessary care.
\end{abstract}

Keywords: Abandonment of Animals. Environmental education. Animal protection.

\title{
Introdução
}

O abandono de animais é um problema mundial e justamente em virtude dessa realidade, é necessário retratar algumas características dessa ação tão reiteradamente executada na atualidade. Observa-se que tal temática é uma das questões que emerge nos estudos sobre o meio ambiente e uma das grandes demandas existentes em matéria de Educação Ambiental, porém, até o momento ela não possui resultados concretos e claros (CARVALHO, 2013).

Assim sendo, o abandono de animais domésticos é caracterizado pelas atitudes oriundas por parte dos próprios donos. Dentre os principais motivos do abandono de animais são indicados: a rejeição da fêmea com cria de filhotes ou àqueles que ficam velhos ou doentes; proprietários que viajam ou mudam de residência e deixam seu pet para trás; cães que crescem e ficam com portes muito grandes ou tornam-se barulhentos (latidos) e/ou ferozes; dificuldade de convívio pela presença de crianças no lar; alergia à pelos, entre outras causas.

Revista Devir Educação, Lavras, vol.2, n.4, p.251-271 jul./dez., 2020. 
Os fatores que envolvem o abandono de animais domésticos são alarmantes, pois em qualquer cidade brasileira é possível encontrar animais abandonados pelas ruas; para tal, as áreas do direito dos animais e a ética ambiental não possuem ainda ferramentas que resolvam e solucionem de modo totalmente eficaz, por si só, este dilema. Dessa forma, as necessidades de sensibilização da sociedade brasileira sobre como se portar diante do abandono de animais domésticos é ainda precária diante das alarmantes demandas (GÓES et al., 2018).

Verifica-se que a Educação Ambiental é uma parte de um todo que está incorporada em um cenário maior, o que vem a produzir e reproduzir as correlações da sociedade, correlações estas com a educação ambiental discutida na escola que também se refletem nas famílias e, respectivamente, na sociedade. Essas correlações possuem sua dependência em uma educação crítica e de vários fatores que acabam por modificar os setores políticos, sociais, econômicos e culturais (SOUZA, 2014).

Compreende-se, ainda, que é de extrema importância que estudos científicos e projetos práticos busquem priorizar a proteção de animais domésticos, juntamente com um pensamento crítico sobre o ambiente no qual vivem esses animais. Nesse sentido, é necessário reconhecer de maneira fundamental quais são os direitos dos animais, buscando-se um repensar em relação ao ambiente social (DZIECIOL; BOSA, 2011). Dessa maneira, os animais domésticos devem possuir seus direitos garantidos pelo Estado e, respectivamente, respeitados por todo cidadão da sociedade brasileira. Importante ressaltar, assim, que é necessário que isso seja demonstrado no direito à vida como um todo, e não apenas no direito inerente ao ser humano. Dito isso, a Educação Ambiental traz uma nova ordem à sociedade em razão das questões pertinentes ao abandono de animais.

Nesse caminho, é necessário trazer as ideias de Singer (2012), que permite uma visão mais aprofundada a respeito do tema trazido pelo estudo, pois busca-se, a partir de seu pensamento, o desenvolvimento de um princípio de igualdade proposto aos animais nãohumanos. Conceitos como o de ser humano, o de pessoa, o de ser senciente ${ }^{4}$, o de ser consciente, autoconsciente, entre outros, são usados em argumentos encadeados de forma simples e clara, levando o leitor a questionar-se sobre as semelhanças e as diferenças existentes entre os animais humanos e não-humanos.

\footnotetext{
${ }^{4}$ Senciência é a capacidade dos seres de sentir sensações e sentimentos de forma consciente. Em outras palavras: é a capacidade de ter percepções conscientes do que lhe acontece e do que o rodeia. A palavra senciência é muitas vezes confundida com sapiência, que pode significar conhecimento, consciência ou percepção.
} 
Assim considerando, o estudo realizou abordagens e atividades na busca da promoção, em uma comunidade escolar da Educação Fundamental, de questões educacionais e ambientais correlatas ao abandono de animais por meio de uma oficina temática, demonstrando, por exemplo, que esse abandono é muito amplo e com muitas consequências, tais como: superpopulação nas ruas, ataques de animais raivosos aos pedestres, ameaças à saúde pública, etc. Outrossim, é importante apresentarmos as etapas que compõem o desenvolvimento de nossa pesquisa: a) seres humanos, animais e meio ambiente; b) o papel das escolas de educação básica na conscientização das crianças; c) resultados e discussão e d) considerações finais.

\section{Seres humanos, animais e meio ambiente}

O reconhecimento do direito ao ambiente sadio configura-se como uma ampliação do direito à vida, quer sobre o ponto de vista da própria existência física e da saúde dos seres humanos, quer ao aspecto da dignidade da existência, no que se refere à qualidade de vida. Tal direito é expresso na Constituição Federal do Brasil, de 1988, no artigo 225, que diz: "Todos têm direito ao meio ambiente ecologicamente equilibrado, bem de uso comum do povo e essencial à sadia qualidade de vida, impondo-se ao Poder Público e à coletividade o dever de defendê-lo e preservá-lo para as presentes e futuras gerações” (BRASIL, 1988).

Ao mesmo tempo, o direito ao meio ambiente ecologicamente equilibrado está entrelaçado com o direito à vida saudável e de qualidade. A necessidade do equilíbrio ecológico é importante para que se possa efetivamente garantir a proteção da personalidade humana. O meio ambiente possui recursos inimagináveis para o desenvolvimento da personalidade humana (REIGOTA, 2002).

Porém, essa personalidade não pode estar dissociada do todo. A visão holística que o ser humano deve ter, coaduna-se com a noção de responsabilidade. Um dos primeiros autores do século XX a defender tal premissa foi Hans Jonas. Em sua obra "Princípio Responsabilidade" (2006), verifica-se que este princípio, além de ser considerado um princípio ético, proporciona uma perspectiva de diálogo crítico em plena era tecnológica. Jonas entende que, sob o signo da tecnologia, a ética tem a ver com o debate sobre as ações 
humanas no presente e no futuro e tudo isso coloca a responsabilidade dos seres humanos no centro de uma preocupação com o planeta e com todos os seres vivos.

Dessa forma, Hans Jonas formulou um novo e característico imperativo categórico, relacionado a um novo tipo de ação humana: "Aja de tal forma que os efeitos de tua ação sejam compatíveis com a permanência de uma vida humana autêntica sobre a Terra" (JONAS, 2006, p. 47). O imperativo proposto por Hans Jonas é de ordem racional para um agir coletivo como um bem público e não só individual. Para Jonas, não se deve ver a destruição física da humanidade como sendo algo mais catastrófico apenas aos humanos, mas para toda a vida terrestre. Se ocorrer, é porque houve uma morte essencial, uma grande desconstrução e crise do ser humano com o meio. Esta sim seria a maior destruição. Não se trata assim só da sorte da sobrevivência do homem, mas do conceito que dele se possui, não só de sua sobrevivência física, mas da integridade de sua essência.

Dessa forma, o princípio responsabilidade faz compreender a existência de várias relações entre a proteção ambiental e o ser humano. Dessa forma, observa-se diante das várias demandas da sociedade em relação ao meio ambiental um rol de aspectos. Entre eles, a qualidade ambiental reflete sobre o momento no qual estamos vivendo em nosso mundo, denominado de momento de risco. Tal problema é corolário das inovações tecnológicas que muitas vezes fogem do controle dos seus criadores. De certa maneira, é possível reconhecer que os avanços tecnológicos devem ser úteis, tornando alguns indispensáveis ao lazer do indivíduo e ao próprio controle de poluição. Porém, o excesso de tecnologia tem desencadeado o lixo eletrônico, a paulatina e progressiva destruição do meio ambiente e, ao mesmo tempo, o abandono com o mundo animal e vegetal.

Não obstante, o meio ambiente ecologicamente equilibrado, de certa forma, possui uma condição importante para o desenvolvimento saudável da vida humana (GUIMARÃES, 2005). Assim sendo, a Educação Ambiental pode contribuir para uma mudança de pensamento, pois ela é um processo permanente de formação, com base no respeito a todas as formas de vida, através das quais, pessoas tomam consciência e assumem a responsabilidade pelo meio ambiente e seus recursos, através da aquisição do conhecimento, de atitudes, valores e motivações que facilitam a compreensão de tão complexos aspectos ecológicos.

Sendo assim, tais conhecimentos devem proporcionar um aprendizado que desperte no indivíduo uma conscientização de que mudanças de atitudes precisam fazer parte do seu diaa-dia e, assim, se passa a formar cidadãos comprometidos com as questões relacionadas ao 
meio ambiente. Segundo Genebaldo Freire Dias, na Primeira Conferência Intergovernamental sobre Educação Ambiental, realizada em 1977, em Tbilisi (na Antiga União Soviética), a Educação Ambiental foi concebida como:

[...] um processo permanente onde os indivíduos e as comunidades tomam consciência do seu meio ambiente e adquirem conhecimentos, habilidades, experiências, valores e a determinação que os tornam capazes de agir, individual ou coletivamente, na busca de soluções para os problemas ambientais, presentes e futuros (DIAS, 2004, p. 92).

Essa consciência é de suma importância para que as pessoas se tornem capazes de agir no sentido de preservar e cuidar do nosso planeta. Além disso, é preciso pensar em alternativas de ações conjuntas e individuais para solucionar problemas que podem interferir direta e indiretamente na vida da população e na poluição do planeta. De acordo com os Parâmetros Curriculares Nacionais,

[...] a principal função do trabalho com o tema Meio Ambiente é contribuir para a formação de cidadãos conscientes, aptos a decidir e atuar na realidade socioambiental de um modo comprometido com a vida, com o bem-estar de cada um e da sociedade local e global. Para isso, é necessário que, mais do que informações e conceitos, a escola se proponha a trabalhar com atitudes, com formação de valores, com o ensino e aprendizagem de procedimentos. $\mathrm{E}$ esse é um grande desafio para a educação (BRASIL, 1998).

Por isso, a urgência da necessidade de colocá-la em prática, para a criação de mudanças de hábitos e para a conscientização da importância da preservação do meio ambiente. Diante disso, acredita-se que a escola através da Educação Ambiental tem grande papel nessa contribuição. Isso pode ser apresentado como essencial já que se vê com grande notoriedade que nos últimos tempos vem ocorrendo um elevado abandono de animais. Tal atitude tem graves consequências e representa uma gama de problemas tais como sofrimento para os animais, perigo para a saúde pública, aumento dos gastos públicos e a superlotação em Organizações Não-governamentais (ONGs) e nos Centros de Controle de Zoonoses (CCZs). Além disso, o risco sanitário ocasionado pela superpopulação de animais errantes, formada pela rápida reprodução de animais maltratados, chama a atenção mundial.

No que tange aos animais abandonados, é preciso considerar que o seu sofrimento é, principalmente, de ordem emocional e física. Como foi apresentado, os animais são seres sencientes. Um animal, nessa situação de maltrato, sente tristeza, medo, estresse e ansiedade, 
pois é deixado em lugares desconhecidos, longe do seu proprietário, que é considerado a sua matilha e fica sujeito a todo tipo de perigo. O sofrimento de ordem física está associado ao fato desses animais serem expostos a todo tipo de perigo, intempéries e doenças, sendo vítimas de zoonoses, doenças carenciais e oportunistas e mutilações (ALMEIDA; ALMEIDA; BRAGA, 2009).

Essa situação é agravada pelo fato de que uma grande parcela dos animais deixados nas ruas ou nos CCZs não apresenta as vacinas em dia e a própria condição de stress, pela qual os animais são expostos, facilita a queda de imunidade e a consequente instalação de infecções. A exposição constante às mudanças climáticas também propicia a queda do bemestar animal (SILVANO et al., 2010).

Outrossim, segundo estimativas da Organização Mundial de Saúde (OMS), há cerca de 500 milhões de cães abandonados no mundo. Apenas no Brasil, a OMS estima que existam 25 milhões de cães e 4 milhões de gatos abandonados. Como consequência desse enorme contingente, tem-se a formação de uma superpopulação de animais errantes (ANDRADE, 2011). Esses animais não têm nenhum tipo de controle de vacinação e tratamento de doenças, funcionando como potenciais transmissores de zoonoses como a raiva e a leishmaniose. Eles também são responsáveis pela proliferação de ectoparasitas, por agressões, acidentes de trânsito, poluição por dejetos, poluição sonora e outras perturbações. (BORTOLOTI; D' AGOSTINO, 2007).

Não obstante, uma consequência grave do abandono que remete tanto à questão humanitária quanto de saúde pública é a percentagem de animais errantes que vai a óbito. A questão humanitária envolve o fato de que muitos animais vão a óbito desnecessariamente devido a atropelamentos sem socorro ou doenças tratáveis, mas que sem os devidos cuidados veterinários se tornam perigosas (BORTOLOTI; D’AGOSTINO, 2007). Muitos proprietários, por sua vez, deixam seus animais nos CCZs mais próximos. Evita-se utilizar aqui o termo "abandono" que significa desistência, falta de amparo ou cuidado. Nesse caso, o guardião deixa o animal com cuidados mínimos que incluem o fornecimento de água, ração e abrigo. A entrega é aceita pelo Estado que passa a assumir a responsabilidade pelo animal. Contudo, isto ainda caracteriza uma guarda irresponsável, uma vez que os proprietários deixam seus animais em ambientes insalubres e sem condições de proporcionar assistência médicoveterinária adequada (HOUAISS, 2001). 
Os CCZs foram projetados como órgãos públicos com o objetivo de minimizar o problema das doenças transmitidas por animais à população humana. Porém, com o decorrer do tempo, as pessoas passaram a utilizar o órgão como destino de animais de estimação que se tornaram indesejados. Como esses centros não têm essa finalidade, a sua estrutura física e de pessoal é insuficiente para comportar todos os animais entregues por causa da prática de uma guarda irresponsável (GARCÍA-RODRIGUES et al., 2008).

Por conseguinte, uma grande quantidade de cães e gatos contraem doenças no canil, devido à ausência de alas isoladas para animais doentes e sadios. Isto, aliado com a entrega de animais doentes e indesejados por seus donos, ainda resulta na eutanásia de uma grande parcela dos animais deixados nos CCZs brasileiros (FRAGA, 2012). A eutanásia dos animais gera desgaste emocional dos funcionários que lidam diariamente com essa situação. Como consequência, há desmotivação pelo trabalho, irritação e o risco de se adquirir zoonose. Nesse contexto, seria conveniente que esses profissionais recebessem acompanhamento psicológico (SOTO, 2010).

As ONGs protetoras dos animais também sofrem as consequências do enorme problema que é o abandono. Essas organizações têm como finalidade principal auxiliar animais em situações de risco, como animais abandonados ou vítimas de maus-tratos. São instituições sem fins lucrativos que se mantêm com a ajuda de voluntários e doações. Um trabalho como este envolve muitos custos com rações, medicamentos e abrigo para os animais resgatados (MATTOS, 2012).

Como vimos, a superpopulação de animais abandonados demanda, cada vez mais, a atuação de ONGs e de protetores independentes. O problema é que nem as organizações nem essas pessoas têm condições de "salvar" todos aqueles que precisam de ajuda. É comum que a maioria das ONGs abrigue mais animais do que efetivamente tem condições financeiras de manter e muitos que lutam pela causa animal transformam suas casas em lares temporários de animais. Como em uma equação lógica, a superpopulação de animais abandonados gera uma superlotação nas ONGs, que ficam impossibilitadas de resgatarem mais animais. Muitas vezes, o próprio bem-estar é prejudicado devido a grande quantidade de animais mantidos nos abrigos. O ápice do problema é atingido quando o trabalho voluntário e as doações não são suficientes para manter o funcionamento de uma ONG.

Dessa maneira, uma questão fundamental desperta o interesse, justamente porque é comum a afirmação de que é preciso agir nas causas e não apenas nos seus efeitos. A questão 
levantada se desdobra na noção de que a educação ambiental (e, nesse caso, o cuidado com os animais) pode ser repensada a partir de uma formação adequada para crianças e adolescentes, pois crê-se que o ato de abandonar um animal é resultante de uma falta. Uma falta que precisa ser preenchida com uma educação sistêmica que inclua a formação de consciências mais amplas e "humanas" de que os animais sentem, sofrem e precisam de cuidados. Sobre isso, várias questões podem ser abordadas, entre elas, merece destaque o papel das escolas na formação das crianças.

\section{O papel das escolas de educação Básica na conscientização das crianças}

A reflexão sobre quem são os animais não humanos não é nova e estava presente na filosofia bem antes da era cristã, mas veio a tomar grande impulso após a publicação do livro "Libertação Animal” de Peter Singer, em 1975. De acordo com Castellano e Sorrentino (2013), a partir daquela década, o campo de estudos e de práticas, que abrangem essas relações, tem se ampliado e realizado alguns avanços, tanto em seu amadurecimento teórico e conceitual, quanto em seu movimento social. Porém, muito ainda precisa ser feito para que a "consciência ambiental e animal" seja conquistada.

É comum as escolas públicas possuírem projetos que enfoquem a temática do meio ambiente, quase que exclusivamente na época de comemoração da famosa semana do Meio Ambiente; no entanto, não discutem as questões animalistas, a não ser o conhecimento simplório de que os animais estão classificados em domésticos e selvagens, as características físicas dos animais, se são mamíferos ou vivíparos, etc. Desse modo, o trabalho com a questão ambiental é um tanto descontextualizado e não problematiza questões como a poluição das águas, a destinação dos lixos, o reaproveitamento e o reuso dos materiais plásticos, dentre outras. Trabalha-se em sala de aula apenas questões teóricas de meio ambiente que não formam as consciências que desejamos para o futuro. Por sua vez, na educação infantil, os animais são apresentados e representados como figuras emblemáticas e ternas.

Além disso, os animais aparecem nas roupas de bebê, na decoração dos espaços infantis e nos desenhos animados de maneira completamente irreal. A crueldade sofrida por 
muitos animais, principalmente os animais de tração, ainda é desconhecida ou ignorada pela maioria das pessoas. Desmistificar e trabalhar cientificamente o direito animal e a educação ambiental-animalista é uma exigência dos tempos atuais. Dessa maneira, é fundamental o investimento em ações pedagógicas, que abordem a garantia de direitos no âmbito da educação e a atual conjuntura sociocultural aponta para a emergência de novos paradigmas na relação homem-natureza.

É relevante salientar a importância da discussão pedagógica sobre essas questões, envolvendo diversas situações cotidianas em rodas de conversa, em aulas de campo, enfim, na convivência dos problemas emergentes do entorno da escola e das comunidades periféricas. Temas que podem ser discutidos e problematizados no dia-a-dia escolar: maus tratos e abandono de animais, o uso dos mesmos para alimentação, fins científicos ou religiosos; os casos em que ocorrem crimes e as situações em que se deve proceder à denúncia, ou seja, todos são aspectos que podem ser trabalhados em todos os níveis da educação básica e nas universidades. Dessa maneira, nosso trabalho definiu-se pela discussão e abordagem do problema dos maus-tratos e abandono dos animais no município de Timbó Grande-SC. Obteve-se um significativo número de informações sobre os objetivos tratados, contudo, a fim de se priorizar algumas informações, delineamos 3 pontos fundamentais (1 - a realização de uma oficina temática, 2 - levantamento de dados e 3 - apresentação de propostas de ação, que serão apresentados no item que segue.

\section{Resultados e discussão}

Participaram do estudo 20 (vinte) alunos de uma turma do $6^{\circ}$ ano do Ensino Fundamental de uma escola de Educação Básica Estadual do município de Timbó Grande, Santa Catarina, com idades aproximadas entre 11 e 12 anos. O instrumento de coleta de dados foi constituído por um questionário contendo 02 (duas) perguntas fechadas, aplicado aos alunos após a atividade de pesquisa. $\mathrm{O}$ instrumento foi aplicado para coletar dados sobre a percepção dos alunos em relação à importância da temática proposta, bem como a relevância de se aplicar o projeto em questão. 
Diante disso, utilizar elementos e conceitos da Educação Ambiental para a promoção do bem-estar animal e diminuir o abandono de animais no município de Timbó Grande-SC, tornou-se um elemento essencial da intenção deste trabalho, pois acreditou-se que era possível trazer aos alunos da Escola de Educação Básica Estadual, aspectos e fatores inéditos para aquele grupo escolar (alunos do $6^{\mathrm{a}}$ ano). Na perspectiva deste trabalho, o aprofundamento das discussões sobre o tema do cuidado dos animais domésticos, facilitou a assimilação de uma visão crítica sobre este problema no município, pois se discutiu por meio da oficina, quais ações e atividades poderiam promover o bem-estar animal para a sociedade local. Assim, levou-se primeiramente em consideração os seguintes objetivos propostos para a execução das atividades: $1^{\circ}$ - proporcionar uma visão ampla e crítica sobre o problema do abandono de animais em Timbó Grande; $2^{\circ}$ - discutir as ações que podem promover o bem-estar animal.

A oficina foi dividida em 3 etapas que foram compreendidas da seguinte forma: a) $\mathrm{Na}$ primeira etapa foi realizada uma apresentação pela professora responsável da oficina, apresentando os objetivos. Foi entregue um termo de consentimento para que os alunos solicitassem aos pais sua participação na oficina. Todos os alunos tiveram interesse em participar das atividades, pois compreenderam a relevância da promoção do bem-estar animal. Dessa forma, foi realizada uma apresentação de cada aluno (dizendo seu nome e se possuía animais de estimação), fazendo assim que houvesse uma interação maior com a temática; b) $\mathrm{Na}$ segunda etapa foi iniciada uma discussão relacionada ao abandono de animais no município de Timbó Grande, retratando que esse abandono é claramente caracterizado por maus tratos aos animais, vindo a refletir na falta de bem-estar desses animais que permanecem em estado de grande vulnerabilidade; c) Na terceira etapa, foi realizada uma discussão com propostas que promovessem o bem-estar dos animais no município como um todo.

Após todas as discussões e interações desenvolvidas, obteve-se algumas informações importantíssimas sobre o tema (com base nas questões levantadas), as quais serão apresentadas sucintamente. No gráfico 1,35\% dos alunos entrevistados responderam que as ações que poderiam promover o mais rápido possível o bem-estar dos animais abandonados no município, seria o cuidado responsável dos animais; $50 \%$ dos pesquisados disseram que seria a adoção de animais (cães e gatos); e 15\% dos alunos responderam que a criação de um grupo de cuidados imediatos a esses animais é fator importantíssimo nesse aspecto. 


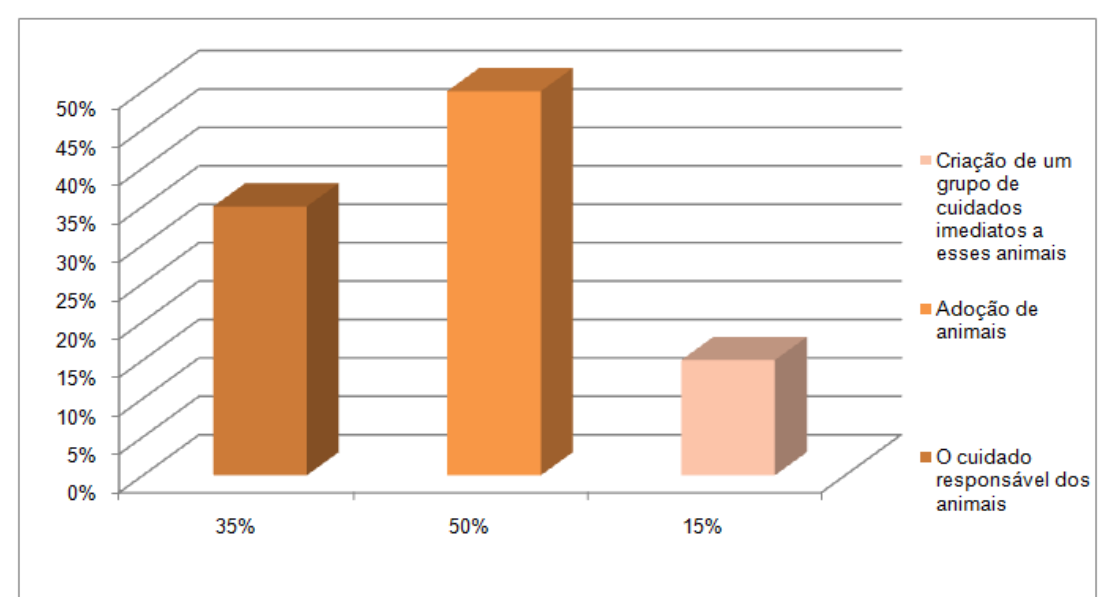

Gráfico 1 - Quais ações você considera importantes para promover o mais rápido possível o bem-estar dos animais abandonados no município?

Fonte: Autora (2020).

Já no Gráfico 2, verificou-se que 75\% (quinze estudantes) dos alunos pesquisados disseram que adotariam "sim" um animal (cão ou gato), para promover o bem-estar dos animais abandonados; e 25\% (cinco estudantes) responderam que não saberiam responder, pois é uma decisão em conjunto (familiar). Quando da realização da oficina temática, em certo momento, foi discutida a importância em se adotar um animal abandonado. Os alunos compreenderam que os animais nas ruas acabam sendo expostos a uma infinidade de situações que prejudicam seu bem-estar.

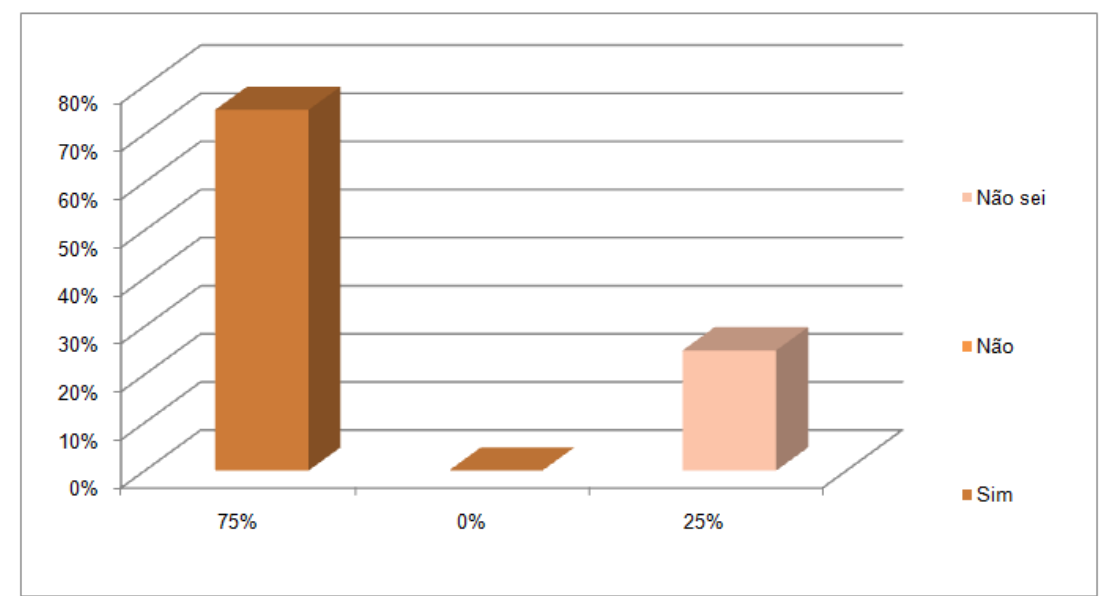

Gráfico 2 - Para promover o bem-estar dos animais abandonados sua família adotaria um cão ou gato?

Fonte: Autora (2020)

Dessa maneira, com base nos dados coletados, a oficina temática trouxe uma melhor compreensão das relações de bem-estar para com os animais abandonados no município de Timbó Grande. A oficina temática se tornou um pequeno núcleo fomentador de propostas e 


\section{OO DEVIR EDUCAÇÃO}

ISSN: 2526-849X

ideias, que visam a facilitar a percepção dos alunos quanto a importância de integrar as variadas áreas do conhecimento, tais como ciência, sociedade e educação ambiental, buscando ainda, a formação de cidadãos críticos e preocupados com a vida como um todo. O cuidado responsável dos animais, juntamente com a adoção desses mesmos animais, e a criação de um grupo de cuidados imediatos a esses animais, após a oficina temática, proporcionaram uma visão além daquelas iniciadas quando da apresentação dos objetivos dessa mesma oficina.

Outrossim, o abandono foi entendido pelos alunos do $6^{\circ}$ ano, como uma problemática de caráter social e ambiental, pois apontaram uma série de complicações decorrentes deste descuido como: a) promovem o surgimento de foco de doenças, b) os animais acabam revirando lixo em busca de alimentos, c) muitas das vezes acabam atacando pessoas nas vias públicas ou calçadas, d) os animais podem ser atropelados ou envenenados, e) podem sofrer maus tratos, passar frio, sede, fome e sofrimento, etc.

Assim sendo, as interações e dos debates entre os estudantes durante a oficina temática, surgiram algumas ideias e decisões que foram efetivadas e serão apresentadas agora:

a) Criação de um documento endereçado à Câmara de Vereadores do município de Timbó Grande, para que seja discutida a criação de uma "Lei de Incentivo à Adoção de Animais Abandonados", tendo os munícipes “adotantes", um desconto em seu Imposto sobre a Propriedade Predial e Territorial Urbana (IPTU), a exemplo de outros municípios catarinenses que já usam de tal legislação (Apêndice A);

b) Criação de um grupo nas redes sociais Facebook, Instagram e WhastApp, coordenados pela professora pesquisadora. Nesses grupos, os alunos poderão discutir soluções, denunciar maus tratos e abandonos, bem como, organizar ações de mobilização para auxiliar animais doentes, receber doações para o cuidado com animais abandonados, sensibilizar a população municipal para os cuidados e o bem-estar dos animais que ainda estão em estado de vulnerabilidade e aprofundar os direitos dos animais, dentre outros temas (Apêndice B);

c) Realização de um levantamento da quantidade de animais que os alunos de toda escola possuem, buscando-se promover a adoção dos filhotes quando de seu nascimento, para que pessoas já cadastradas nos grupos das redes sociais possam participar, bem como, promover a realização de uma promoção de "Adoção de Cães e Gatos" (para todos os munícipes interessados) de maneira consciente, duas vezes ao ano, buscando diminuir o 
abandono de animais no município (Apêndice C). Essa ação deverá ser coordenada pelos alunos da escola, sendo realizada no ambiente escolar.

\section{Considerações finais}

Ao finalizar o estudo proposto, conclui-se que a oficina temática promoveu com êxito a reflexão sobre a importância do bem-estar para com os animais, principalmente, aqueles abandonados e em estado de vulnerabilidade. As ações propostas pelos alunos do $6^{\circ}$ ano fizeram com que a Educação Ambiental se apresentasse como ferramenta operacional de promoção da cidadania, pois do ponto de vista prático, espera-se que as propostas a respeito da proteção aos animais abandonados sejam realizadas.

Assim sendo, os alunos como agentes promovedores da Educação Ambiental no município em questão, compreenderam que devem valorizar e respeitar a vida dos animais, incluindo aí o direito à proteção e aos cuidados básicos de saúde, com base nos princípios teórico-práticos de Hans Jonas e Peter Singer.

Os resultados deste trabalho são de longo prazo e não serão possíveis de serem registrados. Contudo, crê-se que os alunos serão capazes de assumir uma postura ética e cidadã diante dos animais tematizados neste texto, pois segundo relatos, notou-se que provocações para uma educação ambiental foram mobilizadas entre os alunos do $6^{\circ}$ ano. Trata-se agora de retomar periodicamente ações para dar continuidade ao cumprimento das propostas criadas durante a oficina.

Por fim, constatou-se que há uma séria urgência no desenvolvimento de uma nova consciência nos alunos e moradores de Timbó Grande (e, certamente, em todo o mundo), na exata medida em que se percebe que vivemos em um mundo cada vez mais marcado pela importância da responsabilidade. Assim, cuidar de outro ser vivo implica em cuidar de si mesmo.

Assim, esse cuidado não é uma obrigação impositiva e legalista; é, antes de mais nada uma necessidade que garante a existência da vida humana, da vida animal e da vida vegetal em uma casa comum, que é o planeta Terra. Zelar, cuidar e proteger são verbos que os seres humanos precisam conjugar para garantir um futuro que se faz presente agora, no que se 
refere aos animais e a todos os seres do planeta. Dessa maneira, iniciativas já foram tomadas em relação ao cuidado pelos animais, mas igualmente ainda se tem muitas ações por se fazer.

\section{Referências}

ALMEIDA, Maria Lopes de; ALMEIDA Laerte Pereira de; BRAGA, Paula Fernanda de Souza. Aspectos psicológicos na interação homem: animal de estimação. Uberlândia: Universidade Federal de Uberlândia, 2009.

ANDRADE, Wilza de Fatima. Implantação do centro de controle de zoonoses: um espaço público para o resgate de animais abandonados. Colombo: Universidade Federal do Paraná, 2011.

BORTOLOTI, Renato; D'AGOSTINO, Renata Grotta. Ações pelo controle reprodutivo e posse responsável dos animais domésticos interpretadas à luz do conceito de metacontingência. Revista Brasileira de Análise do Comportamento, v.3, n.1, p.17-28, 2007.

BRASIL. Parâmetros Curriculares Nacionais: Meio Ambiente. Brasília: MEC, 1998. . Constituição da República Federativa do Brasil, de 05 de outubro de 1988.

CARVALHO, Adriana Beatriz de. Abandono e maus tratos de animais no contexto da Educação Ambiental: o uso do Facebook. Curitiba: Universidade Federal do Paraná, 2013.

CASTELLANO, Maria, SORRENTINO, Marcos. Como ampliar o diálogo sobre abolicionismo animal: contribuições pelo caminho da educação e das políticas públicas. Revista Brasileira de Direito Animal - RBDA, Salvador, v.8, n.14, 2013.

DIAS, Genebaldo Freire. Educação Ambiental: princípios e práticas. 9 ed. São Paulo: Gaia, 2004.

DZIECIOL, Merjorie Eloise; BOSA, Cláudia Regina. O programa de guarda responsável de animais de Curitiba e sua aplicação no acantonamento ecológico. REMOA, v.4, n.4, p.877886, 2011.

FRAGA, Lívia dos Santos. Controle de zoonoses: estudo sobre práticas educativas e o manejo voltado ao controle da população canina. Rio de Janeiro: Escola Nacional de Saúde Pública Sergio Arouca, Fiocruz, 2012.

GARCÍA-RODRIGUES, Alejo; PERACHO, Víctor; VILLALBÍ, Joan R.; BOUIS, Susana; DURÀN, Julia; GUIX, Joan. Avanços na gestão de um abrigo para animais de estimação. Gaceta Sanitaria, v. 22, n. 1, p. 76-78, 2008. 
GÓES, Querina Ramos; BARBOSA, Beatriz Wardzinski; FLORES, Josiane Martins; NUNES, Rosângela Silva Gonçalves; WEBER, Mirla Andrade. Educação para a conscientização sobre animais domésticos e silvestres. Rev. Ciênc. Ext., v.14, n.2, p.114-127, 2018.

GUIMARÃES, Mauro. A Dimensão Ambiental na educação. Campinas: Papirus, 2005.

HOUAISS, Antonio. Mini Houaiss Dicionário da Língua Portuguesa. Rio de Janeiro: Objetiva, 2001.

JONAS, Hans. O princípio responsabilidade: ensaio de uma ética para a civilização tecnológica. Tradução de Marjane Lisboa e Luiz Barros Montez, Rio de Janeiro: Contraponto. Ed. PUC-Rio, 2006.

MATTOS, Liziane Gonçalves de. A ajuda animalitária quando o outro é um animal: um estudo antropológico sobre sensibilidades e moralidades envolvidas no cuidado e proteção de animais abandonados a partir de Porto Alegre/RS. Porto Alegre: Universidade Federal do Rio Grande do Sul, 2012.

REIGOTA, Marcos. Meio ambiente e representação social. São Paulo: Cortez, 2002.

SILVANO, D.; BENDAS, A. J. R.; MIRANDA, M. G. N.; PINHÃO, R.; MENDES-DEALMEIDA, F.; LABARTHE, N. V.; PAIVA, J. P. Divulgação dos princípios da guarda responsável: uma vertente possível no trabalho de pesquisa a campo. Revista Eletrônica Novo Enfoque, v.9, n.9, p.64-86, 2010.

SINGER, Peter. Ética Prática. Trad. Manuel Joaquim Vieira. Lisboa: Tipografia Lugo, 2012.

Libertação animal: o clássico definitivo sobre o movimento pelos direitos dos animais. São Paulo: Editora WMF Martins Fontes, 2013.

SOTO, Francisco Rafael Martins. Eutanásia canina nos centros de controle de zoonoses. Arquivo de Ciências Veterinárias e Zoologia da UNIPAR, Umuarama, v.13, n.1, p.43-46, Jan./Jun., 2010.

SOUZA, Alinne Silva de. Direitos dos animais domésticos: análise comparativa dos estatutos de proteção. Rev. Direito Econ. Socioambiental, Curitiba, v.5, n.1, p.110-132, Jan./Jun., 2014. 


\title{
APÊNDICE A - DOCUMENTO ENDEREÇADO À CÂMARA DE VEREADORES DO MUNICÍPIO DE TIMBÓ GRANDE, PARA QUE SEJA DISCUTIDA A CRIAÇÃO DE UMA "LEI DE INCENTIVO A ADOÇÃO DE ANIMAIS ABANDONADOS
}

Timbó Grande (SC), 20 de abril de 2020.

\section{Ao Senhor Presidente da Câmara de Vereadores de Timbó Grande, Santa Catarina}

Venho por meio desta, solicitar a vós o auxílio na criação de uma "Lei de Incentivo a Adoção de Animais Abandonados", tendo os munícipes "adotantes", um desconto em seu Imposto sobre a Propriedade Predial e Territorial Urbana (IPTU), a exemplo de outros municípios catarinenses que já usam de tal legislação. Os alunos da $6^{a}$ série do Ensino Fundamental da Escola de Educação Básica Estadual Machado de Assis, possuem um projeto de promoção da adoção de animais abandonados no município, e na certeza que podemos contar com vosso auxílio, ficamos no aguardo.

Cordialmente,

\author{
SUNAH JESSIE MAKIOLKI \\ Professora Coordenadora do Projeto
}

Revista Devir Educação, Lavras, vol.2, n.4, p.251-271 jul./dez., 2020. 


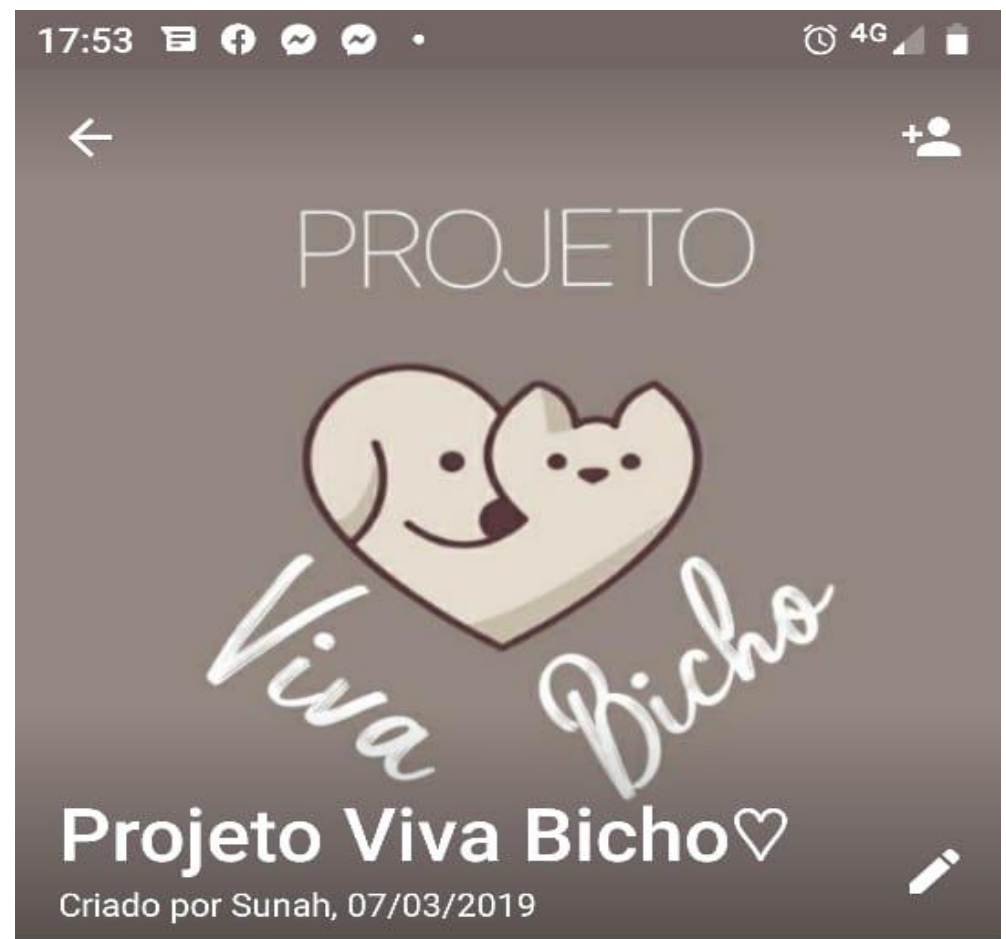

Adicionar descrição ao grupo

Mídia, links e docs

$501>$
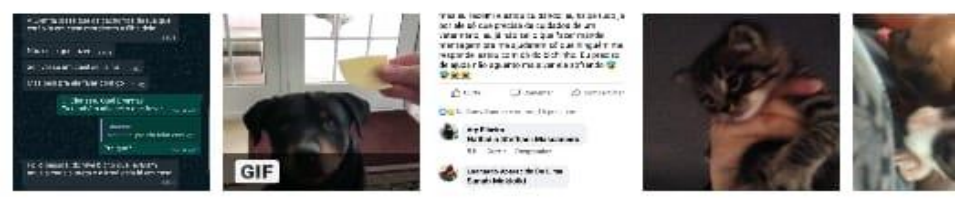

\section{Silenciar notificações}

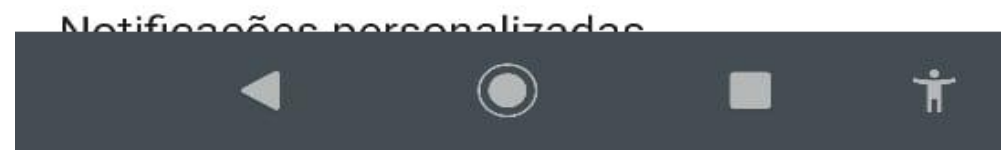

Figura 3 - Grupo no WhatsApp do Projeto Viva Bicho.

Revista Devir Educação, Lavras, vol.2, n.4, p.251-271 jul./dez., 2020. 


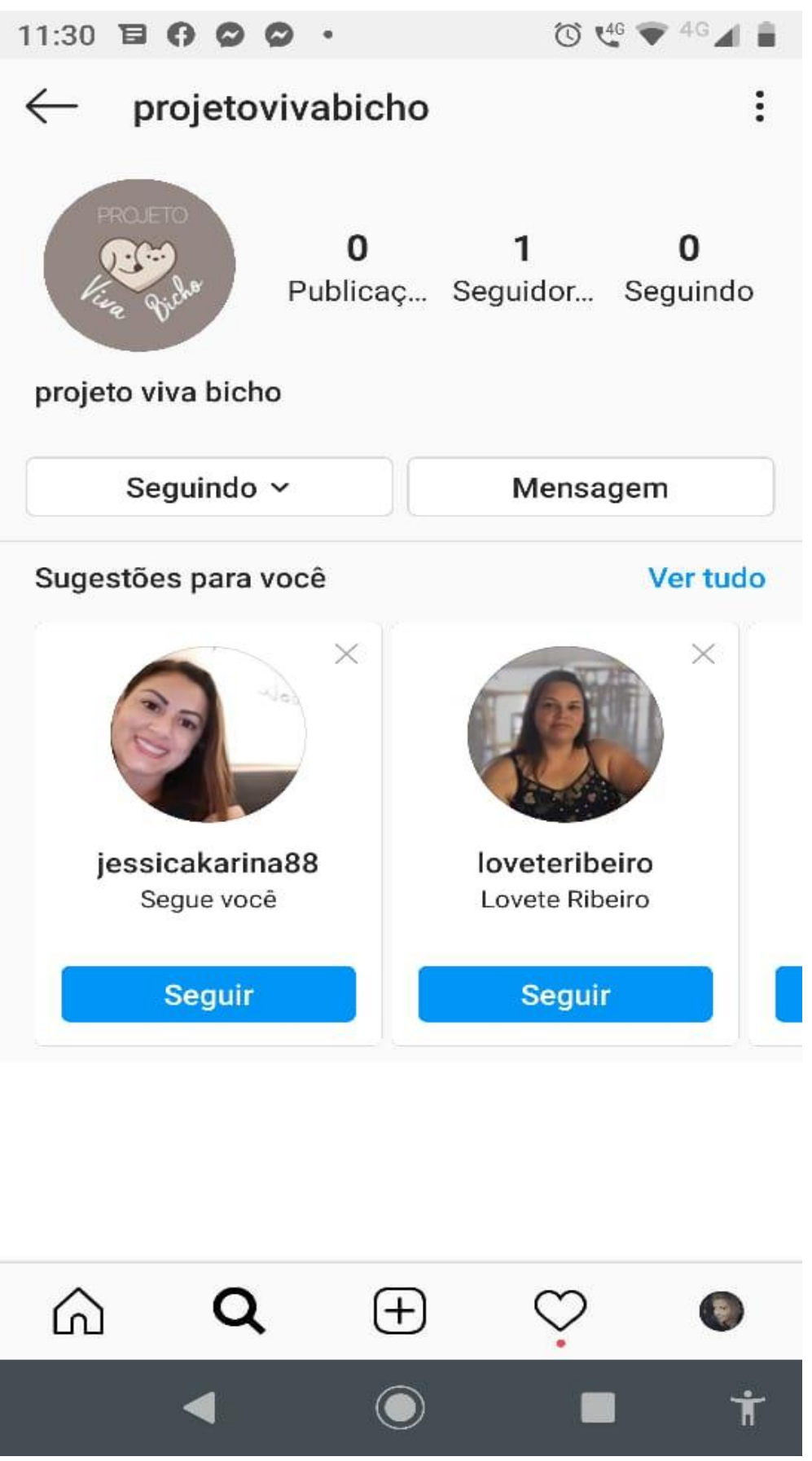

Figura 4 - Instagram do Projeto Viva Bicho.

Revista Devir Educação, Lavras, vol.2, n.4, p.251-271 jul./dez., 2020. 


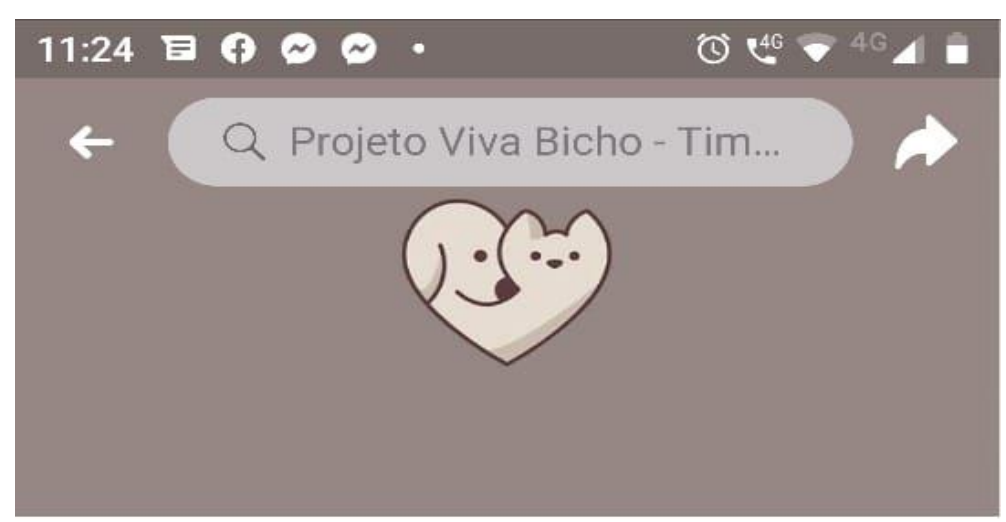

Projeto Projeto Viva Bicho Timbó Grande/SC

raguean 22 Seguido por Eliane, Marli, Daiana e outras 340 pessoas

ágina inicial Sobre Eventos Fotos Vídeos C

\section{Próximos eventos}

Nenhum evento próximo

\section{Eventos anteriores}

JUN Cachorro quente solidário

044 de jun de 2019 às 17:00 BRT

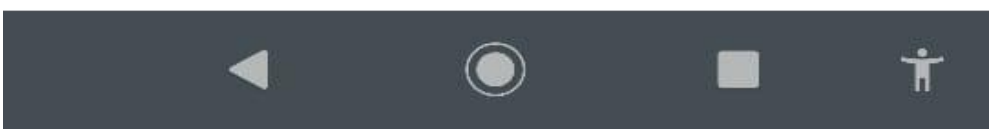

Figura 5 - Facebook do Projeto Viva Bicho.

Revista Devir Educação, Lavras, vol.2, n.4, p.251-271 jul./dez., 2020. 
APÊNDICE C - LEVANTAMENTO DA QUANTIDADE DE ANIMAIS DOS ALUNOS

Tabela 1 - LEVANTAMENTO DA QUANTIDADE DE ANIMAIS DOS ALUNOS

\begin{tabular}{cc}
\hline Animais & Quantidade \\
\hline Cães & 15 \\
Gatos & 09 \\
Total & 24 \\
\hline
\end{tabular}

Recebido em: 24/09/2020

Aprovado em: 10/11/2020

Revista Devir Educação, Lavras, vol.2, n.4, p.251-271 jul./dez., 2020. 